\title{
Assessment of the potential for host-targeted iminosugars UV-4 and UV-5 activity against filovirus infections in vitro and in vivo
}

Kelly L. Warfield ${ }^{\mathrm{a}, *}$, Travis K. Warren ${ }^{\mathrm{b}}$, Xiangguo Qiuc ${ }^{\mathrm{c}}$, Jay Wells ${ }^{\mathrm{b}}$, Chad E. Mire ${ }^{\mathrm{d}}$, Joan B. Geisbert ${ }^{d}$, Kelly S. Stuthman ${ }^{b}$, Nicole L. Garza ${ }^{b}$, Sean A. Van Tongeren ${ }^{b}$, Amy C. Shurtleff ${ }^{b}$, Krystle N. Agans ${ }^{d}$, Gary Wong ${ }^{c, e}$, Michael V. Callahan ${ }^{f, g}$, Thomas W. Geisbert $^{d}$, Brennan Klose ${ }^{\dagger}$, Urban Ramstedt ${ }^{\dagger}$ and Anthony M. Treston ${ }^{a}$

a Emergent BioSolutions, Gaithersburg, MD 20879, USA;

b United States Army Research Institute of Infectious Diseases (USAMRIID), Fort Detrick, MD, 21702, USA;

c Special Pathogens Program, National Microbiology Laboratory, Public Health Agency of Canada, Winnipeg, Manitoba R3E 3R2

d University of Texas Medical Branch, Galveston National Laboratory, Galveston, TX, 77550, USA;

e CAS Key Laboratory of Pathogenic Microbiology and Immunology, Institute of Microbiology, Chinese Academy of Sciences, Beijing, China

f Unither Virology LLC, Silver Spring, MD 20910, USA;

9 Division of Infectious Diseases, Massachusetts General Hospital/Harvard Medical School, Boston, MA

*Corresponding author: K. Warfield; warfieldk@ebsi.com; Emergent BioSolutions, Inc., 400 Professional Drive, Gaithersburg, MD 20879; (240) 631-3575

Email Addresses: warfieldk@ebsi.com (K. Warfield), travis.k.warren.ctr@mail.mil (T. Warren), Xiangguo.qiu@phac-aspc.gc.ca (X. Qiu), jay.b.wells.ctr@mail.mil (J.Wells), cmire@utmb.edu (Chad Mire), jbgeisbe@utmb.edu (J. Geisbert), Kelly.s.stuthman.ctr@mail.mil (K. Stuthman), nicole.l.lackemeyer.ctr@mail.mil (N. Garza), sean.a.vantongeren.ctr@mail.mil (S. Van Tongeren), amy.c.shurtleff.ctr@mail.mil (A. Shurtleff), knagans@utmb.edu (K. Agans), garyckwong@hotmail.com (G. Wong), mvcallahan@mgh.harvard.edu (M. Callahan), twgeisbe@utmb.edu (T. Geisbert), brennan.klose@abviro.com (B. Klose), urban_ramstedt@yahoo.com (U. Ramstedt) and trestona@ebsi.com (A. Treston)

Content: Abstract word count, 247; Text word count, 5,123; 33 references; 7 figures; 2 tables, 4 supplementary tables. 
Keywords: Iminosugar; UV-4B; Ebola virus; Marburg virus; antiviral; glucosidase 


\section{ABSTRACT}

Iminosugars are host-directed antivirals with broad-spectrum activity. The iminosugar, $\mathrm{N}$-butyl-deoxynojirimycin (NB-DNJ or Miglustat ${ }^{\circledR}$ ), is used in humans for treatment of Gaucher's disease and has mild antiviral properties. More potent analogs of NB-DNJ have been generated and have demonstrated activity against a variety of viruses including flaviviruses, influenza, herpesviruses and filoviruses. In the current study, a panel of analogs based on NB-DNJ was analyzed for activity against Ebola (EBOV) and Marburg viruses (MARV). The antiviral activity of NB-DNJ (UV-1), UV-2, UV-3, UV-4 and UV-5 against both EBOV and MARV was demonstrated in Vero cells. Subsequent studies to examine the activity of UV-4 and UV-5 using rodent models of EBOV and MARV were performed. In vivo efficacy studies provided inconsistent data following treatment with iminosugars using filovirus mouse models. A tolerability study in nonhuman primates demonstrated that UV-4 could be administered at much higher dose levels than rodents. Since UV-4 was active in vitro, had been demonstrated to be active against influenza and dengue in vivo, and was being tested in a Phase 1 clinical trial, a small proof-of-concept nonhuman primate trial was performed to determine whether this antiviral candidate could provide clinical benefit to EBOV-infected individuals. Administration of UV-4B did not provide a clinical or survival benefit to macaques infected with EBOV-Makona; however, dosing of animals was not optimal in this study. Efficacy may be improved by thrice daily dosing (e.g. by nasogastric tube feeding) to match the efficacious dosing regimens demonstrated against dengue and influenza viruses. 


\subsection{INTRODUCTION}

The family Filoviridae consists of eight viruses including Ebola (EBOV) and Marburg (MARV) viruses. Between their initial discovery in 1967 and the end of 2013, human filovirus disease outbreaks occurred sporadically in Equatorial Africa and included only small numbers of infections, but had high case-fatality rates (Hartman et al., 2010; Slenczka, 1999). However, in 2014, EBOV (Makona) was identified as the cause of a large outbreak in West Africa that resulted in $>28,000$ cases and $>11,000$ deaths reported to the World Health Organization to date (Organization). Following infection with a filovirus, an initial viral prodrome consisting of arthralgias, fatigue, fever, headache, and myalgias is followed by anorexia, nausea, vomiting, diarrhea, and abdominal pain (Leligdowicz et al., 2016). The case fatality proportion in the 2014-16 West African outbreak was approximately $40 \%$ with the most frequent causes of death being hypovolemia, uncompensated metabolic acidosis, severe hypokalemia and hypomagnesemia and septic shock. Death presents as multisystem organ dysfunction/failure (Leligdowicz et al., 2016). To date there are no approved therapeutics to treat filovirus-infected patients or any preventative vaccines. Therefore, during the West African outbreak, a number of experimental drugs were administered under compassionate use authorization with the hope of decreasing morbidity and mortality. The drugs that were administered were generally poorly characterized for their safety or efficacy profile and several with little to no in vitro antiviral activity against EBOV were studied as the only available options offering any possibility of improving survival benefit in infected patients. Late in the outbreak, a number of more controlled Phase II/III clinical trials were launched to test the efficacy of a variety of small-molecule 
drugs, RNA-based treatments, and antibody-based therapies to find promising candidates (Mendoza et al., 2016).

Iminosugars are carbohydrate mimetics with positive drug-like properties that have been well known for many years. These molecules are a class of non-covalent inhibitors which are known to be relatively innocuous to the host. Iminosugars inhibit endoplasmic reticulum (ER) a-glucosidases required for glycoprotein processing. Inhibition of the ER a-glucosidases results in misfolded proteins being catabolized in the proteasome (Dwek et al., 2002). This mechanism has been demonstrated by increased levels of free oligosaccharides produced by proteosomal degradation and elimination after treatment of cells with iminosugars (Alonzi et al., 2008). Importantly, binding is reversible and clearance of drug and return of host enzyme functions is rapid after cessation of dosing (Alonzi et al., 2008; Lachmann, 2003). Several iminosugars are already approved for oral delivery and continuous, long-term use including Miglustat $\AA$ for Gaucher's Disease and Miglitol囚 for diabetes (Dalziel et al., 2014; Lachmann, 2003). Miglustat ${ }^{\circledR}$ or $\mathrm{N}$-butyl-deoxynojirimycin, (NB-DNJ), has mild antiviral properties but pharmacologically relevant levels for antiviral activity are not able to be achieved in humans due to tolerability issues (Branza-Nichita et al., 2001a; Karlsson et al., 1993; Perry et al., 2013).

A recent publication validates the ER protein folding pathway as a target for antiviral drugs (Sadat et al., 2014). Congenital disorder of glycosylation (CDG)-Ilb is a genetic disorder affecting the $\mathrm{N}$-glycosylation process and results in a defect in processing of $\mathrm{N}$ glycans due to an absence of functional ER a-glucosidase I (mogs -/-). Sadat et al. described two siblings with CDG-Ilb who have a spectrum of developmental 
abnormalities but no history of viral disease in spite of significant hypogammaglobulinemia (Sadat et al., 2014). Both siblings lacked antibodies to immunizations with live viruses (measles, mumps, rubella, and varicella zoster) but had immune responses to polysaccharide and protein based vaccines. To probe the lack of obvious virus infections in these children, cells from the siblings with CDG-Ilb were collected and tested for susceptibility to four strains of HIV, INFV A (H1N1), and Adenovirus type 5. None of these viruses was able to productively infect cells derived from the two siblings although the viruses were able to infect cells from healthy donors. These findings provide validation that targeting ER a-glucosidases is expected to show activity against viral infections, specifically those that utilize the host glycosylation machinery for replication (Chang et al., 2013a).

Since iminosugars have antiviral activity through a host based mechanism, they offer an attractive avenue for developing antiviral therapies against a diverse range of viruses that utilize host glycosylation pathways for replication (Chang et al., 2013a; Dalziel et al., 2014). Analogs of DNJ have been generated by various groups and have demonstrated activity against a variety of viruses including flaviviruses, influenza, herpesviruses, and filoviruses. Chang et al. recently reported on a series of molecules related to DNJ that inhibited EBOV and MARV replication in cells and reduced mortality of mice infected with mouse-adapted strains of both viruses (Chang et al., 2013c). Three novel iminosugars (IHVR-11029, -17028 and -19029) were identified following extensive structural-activity relationship studies from 120 molecules, which demonstrated antiviral activity against diverse viruses that cause hemorrhagic fever including EBOV, dengue, Tacaribe, Lassa and Rift Valley Fever viruses. These 
compounds partially protected mice against lethal filovirus infection when administered intraperitoneally, but were not orally bioavailable.

Targeting host enzymes may allow novel antivirals to overcome several liabilities of direct-acting antivirals. The ER $\alpha$-glucosidase enzyme targets of iminosugar platform have been shown to be critical for efficient replication of a variety of viral families and these families are known to require processing by this host pathway in order to produce properly-glycosylated coat and nonstructural proteins (Branza-Nichita et al., 2001a; Lazar et al., 2007; Rathore et al., 2011; Saito and Yamaguchi, 2000). Additionally, targeting host enzymes is known to result in reduced likelihood of selection of resistant viral strains. This has been demonstrated for iminosugars acting against both HIV and dengue (Plummer et al., 2015; Pollock et al., 2008).

In the current study, a panel of analogs based on NB-DNJ was analyzed for activity against Ebola (EBOV) and Marburg viruses (MARV). The antiviral activity of NB-DNJ (UV-1), UV-2, UV-3, UV-4 and UV-5 against filoviruses EBOV and MARV was tested. UV-4 was of significant interest, since it is already being tested in humans (https://clinicaltrials.gov/ct2/show/NCT02061358). If found to be active against EBOV, UV-4 could potentially have been more quickly transitioned into compassionate use cases during the 2014-16 or used in potential, future outbreaks of EBOV than other preclinical drug candidates. 


\subsection{METHODS}

Iminosugar compounds. A panel of iminosugars were tested and included $N$ butyldeoxynojirimycin (NB-DNJ; also known as miglustat or UV-1), N-nonyl-DNJ (UV-2), N-7-oxadecyl-DNJ (UV-3), N-9-methoxynonyl-DNJ (UV-4), and N-(N-4-azido-2nitrophenyl)-6-aminohexyl-DNJ (UV-5) (Perry et al., 2013). For in vitro testing, iminosugars were prepared as DMSO stocks and then diluted to the appropriate concentrations. Acidified water was used to prepare UV-4 for administration to mice or UV-5 for administration to mice and guinea pigs, as previously described (Perry et al., 2013). For guinea pigs and nonhuman primates, a hydrochloride salt named UV-4B was used to prepare dosing formulations; the dose levels for these studies are expressed as the active free base form, UV-4.

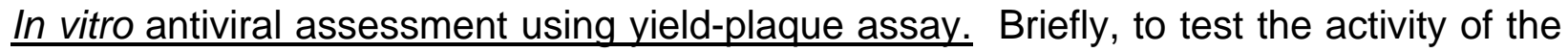
iminosugars UV-1, UV-2, UV-3, UV-4 and UV-5 against EBOV (Zaire-Kikwit) or MARV (Ci67), a yield-plaque assay was conducted in Vero cells. Multiple concentrations of compounds were incubated on 24-well plates of Vero cells for 1 h at 8 concentrations (2 fold dilutions starting at $62.5 \mu \mathrm{M})$. After $\sim 1 \mathrm{~h}$, pretreatment medium was aspirated and virus inoculums added (MOI of 0.1 with EBOV or MARV). After an additional hour of infection, virus inoculum was removed (no washing) and $1 \mathrm{~mL}$ of compound medium was added at the final concentration. After incubation for 72 hours, supernatants were harvested and competent viral particles released from the cells were enumerated by plaque assay (Moe et al., 1981) in duplicate. Percent inhibition was determined by comparing DMSO-treated cells (average value) infected with virus to those treated with 
compound at the various concentrations. The $50 \%$ inhibitory concentrations $\left(\mathrm{IC}_{50}\right)$ were calculated using GraphPad Prism based on the \% inhibition at each concentration.

Efficacy testing of UV-4B and UV-5 in mouse models of filovirus infections. Mouseadapted EBOV (Bray et al., 1998) and MARV-Ravn (Warfield et al., 2009) were used to infect female $\mathrm{C} 57 \mathrm{BI} / 6$ or $\mathrm{BALB} / \mathrm{c}$ mice with target challenge dose of 1000 pfu via intraperitoneal injection. UV-4 (free base) and UV-5 were prepared in acidified water for oral gavage (PO) or in phosphate buffered saline (PBS) for intraperitoneal infection (IP) and subcutaneous (SQ) delivery. UV-4 or UV-5 were administered via PO, IP or SQ for 7-10 days starting 30-60 minutes before virus challenge at $5,10,20$, or $100 \mathrm{mg} / \mathrm{kg}$ or vehicle only (water for PO or PBS for IP delivery). Compounds were administered either twice (BID) or three times (TID) daily at 12 or 8 hour intervals, respectively. Weights, morbidity and mortality were monitored for up to 21 days. Animals which displayed severe illness were euthanized based on predefined scoring systems.

The mouse efficacy studies were conducted according to research protocols approved by the USAMRIID Institutional Animal Care and Use Committee (IACUC). This was in compliance with the Animal Welfare Act and other federal statutes and regulations relating to animals and experiments involving animals and adhered to the principles stated in the Guide for the Care and Use of Laboratory Animals, National Research Council, 2011. The facility where this research was conducted is fully accredited by the Association for the Assessment and Accreditation of Laboratory Animal Care International (AAALAC). All challenge studies were conducted under maximum containment in a biosafety level 4 (BSL-4) facility at USAMRIID. 
Efficacy testing of UV-4B in a lethal EBOV guinea pig model. To assess the efficacy of UV-4B in female Hartley guinea pigs ( $n=4$ /group) were treated orally with vehicle, 6, 12 or $24 \mathrm{mg} / \mathrm{kg}$ of UV-4B TID PO starting 1 day before infection for 7 days. Guinea pigs were infected IP with guinea pig-adapted EBOV at a target dose of $1000 \times L_{50}$. Weights, morbidity and mortality were monitored for up to 21 days. Animals which displayed severe illness were euthanized. The EBOV guinea pig efficacy study was performed in the BSL-4 facility at the National Microbiology Laboratory located in Winnipeg, Canada, and was approved by the Animal Care Committee (ACC) based at the Canadian Science Center for Human and Animal Health (CSCHAH), in accordance with Canadian Council on Animal Care (CCAC) guidelines.

Efficacy testing of UV-5 in a lethal MARV guinea pig model. A study was conducted to test the ability of UV-5 to protect Hartley guinea pigs from lethal MARV infection. UV-5 was delivered via intramuscular (IM) or IP injection twice daily at $40 \mathrm{mg} / \mathrm{kg}$ for a total of 10 days. A control group of guinea pigs treated with vehicle (PBS) only was also included. Weights, health and survival were monitored for up to 21 days after infection with $\sim 1000$ plaque forming units (pfu) of guinea pig-adapted MARV and animals which displayed severe illness were euthanized. The MARV guinea pig study was conducted under a protocol approved by the UTMB IACUC. IACUC approval of animal studies performed at UTMB is in compliance with the Animal Welfare Act, PHS Policy, and other Federal statutes and regulations relating to animals and experiments involving animals. The facilities where this research was conducted are accredited by AAALAC and adhere to principles stated in the eighth edition of the Guide for the Care and Use of Laboratory Animals, National Research Council. 
Tolerability and pharmacokinetic analysis of UV-4 administration in macaques. Three female monkeys, aged $2.5-4.5$ years, were dosed TID via nasogastric intubation for five days at a dose of $20 \mathrm{mg} / \mathrm{kg}$. Following a washout period of nine days, the same animals were dosed TID via nasogastric intubation for five days at a dose of $60 \mathrm{mg} / \mathrm{kg}$. The third dose cycle (following a washout period of nine days) increased the dose to $180 \mathrm{mg} / \mathrm{kg}$ and dosing was extended to ten days, which was anticipated to be a length of dosing to be used in an efficacy study with EBOV.

Observations for all monkeys included physical examinations and body weights prior to the initiation of each dose cycle, daily during the dosing period, and once during the non-dosing periods. Post-dose observations were recorded $30 \pm 10$ minutes postdose for all first and second daily doses. Cage-side observations were performed twice daily and qualitative food consumption was recorded daily.

In addition to clinical observations, fasted blood samples were collected for clinical chemistry and hematology prior to and at specified intervals during each dose cycle. Total white blood cell counts (WBC), erythrocyte count, reticulocyte count, leukocyte count, platelet count (PLT), red blood cell counts (RBC), red cell distribution width, hematocrit values $(\mathrm{HCT})$, total hemoglobin concentrations $(\mathrm{HgB})$, mean cell volumes (MCV), mean platelet volume (MPV), mean corpuscular volumes (MCV), and mean corpuscular hemoglobin concentrations $(\mathrm{MCHC})$ were analyzed from blood collected in tubes containing EDTA using a laser based hematologic analyzer (Beckman Coulter). Serum samples were tested for concentrations of albumin (ALB), alanine aminotransferase (ALT), aspartate aminotransferase (AST), alkaline phosphatase (ALP), blood urea nitrogen (BUN), calcium (CA), chloride, cholesterol, creatinine (CRE), 
creatine kinase (CK), enzymatic carbon dioxide, gamma-glutamyltransferase (GGT), globulin, glucose, phosphorus, potassium, sodium, total protein (TP), total bilirubin (TBIL), and triglycerides.

Blood samples (not fasted) were collected prior to and at specified intervals during each dose cycle for pharmacokinetic analysis. The samples were analyzed using a LCMSMS method previously validated for human plasma and qualified for nonhuman primate plasma as part of the bioanalysis of these samples (performed by Quintiles, Ithaca, NY).

This nonhuman primate study was conducted under a protocol approved by the Smithers-Avanza IACUC. IACUC approval of animal studies performed at this site, which is accredited by the Association for Assessment and Accreditation of Laboratory Animal Care, International, is in compliance with provisions of the USDA Animal Welfare Act, the PHS Policy on Humane Care and Use of Laboratory Animals and the U.S. Interagency Research Animal Committee Principles for the Utilization and Care of Research Animals.

Efficacy testing of UV-4B in a nonhuman primate model of EBOV infection. The EBOV Makona strain seed stock originated from serum from a fatal case early during the 2014 outbreak in Guékédou, Guinea (C07 isolate, NCBI Accession \# KJ660347) and was passaged twice in Vero E6 cells (ATCC, CRL-1586). The virus stock was deep sequenced as $100 \% 7 \mathrm{U}$ at the GP editing site in the viral genome (Mire et al., 2015, Nature). Four rhesus monkeys were exposed to a target dose of 1000 pfu (backtitration by plaque assay revealed 1113 pfu was the challenge dose) of EBOV-Makona 
virus by IM injection in $0.5 \mathrm{~mL}$ volume at a single site. Monkey 1204218 was female; 1205199 and 1207127 were male; and the control KB78 was female. Due to potential issues for laboratory worker safety during multiple handlings of EBOV-infected primates and requirements for anesthesia when animals are removed from the cages, only a single dose per day was allowed to be given by oral gavage. Therefore, three animals were treated PO once daily with $180 \mathrm{mg} / \mathrm{kg}$ of UV-4B and two additional doses of 180 $\mathrm{mg} / \mathrm{kg}$ were attempted per day by spiking food or liquid (e.g., Pedialyte) on days 0-9 after exposure. A single naïve, untreated control animal was shared with another concurrent study. All animals were given physical exams and blood was collected at the time of challenge and on days $3,6,10,14,22$, and 28 after EBOV challenge or at time of euthanasia. The volume of blood collected was determined by weight of animals and did not exceed $10 \%$ of the total circulating blood volume during a 2 week period. Calculations were performed utilizing the average total circulating blood volume, which was equal to $5.5-7.0 \%$ of the animal's body weight $(\sim 66 \mathrm{ml} / \mathrm{kg})$.

All animals were monitored and scored for disease progression with an internal filovirus scoring protocol approved by the UTMB IACUC. The scoring changes measured from baseline included posture/activity level, attitude/behavior, food and water intake, weight, respiration, and disease manifestations such as visible rash, hemorrhage, ecchymosis, or flushed skin. A score of $\geq 9$ indicated that an animal met criteria for euthanasia. This study was not blinded.

The nonhuman primate study was conducted under a protocol approved by the UTMB IACUC. IACUC approval of animal studies performed at UTMB is in compliance with the Animal Welfare Act, PHS Policy, and other Federal statutes and regulations 
relating to animals and experiments involving animals. The facilities where this research was conducted are accredited by AAALAC and adhere to principles stated in the eighth edition of the Guide for the Care and Use of Laboratory Animals, National Research Council.

For determination of viremia, both quantitative reverse transcriptase polymerase chain reaction (qRT-PCR) and plaque assays were used. RNA was isolated from whole blood or tissues utilizing the Viral RNA Mini Kit or RNeasy Kit (Qiagen) using $100 \mu \mathrm{L}$ of blood into $600 \mu \mathrm{L}$ of buffer AVL, per manufacturer's instructions. Primers/probe targeting the VP30 gene of EBOV were used for qRT-PCR with the probe used here being 6-carboxyfluorescein (6FAM)- 5'- CCG TCA ATC AAG GAG CGC CTC 3' - 6 carboxytetramethylrhodamine (TAMRA) (Life Technologies). EBOV RNA was detected using the CFX96 detection system (BioRad Laboratories) in One-step probe qRT-PCR kits (Qiagen) with the following cycle conditions: $50^{\circ} \mathrm{C}$ for 10 minutes, $95^{\circ} \mathrm{C}$ for 10 seconds, and 40 cycles of $95^{\circ} \mathrm{C}$ for 10 seconds and $59^{\circ} \mathrm{C}$ for 30 seconds. Threshold cycle (CT) values representing EBOV genomes were analyzed with CFX Manager Software, and data are shown as means \pm SD of technical replicates. To create the GEq standard, RNA from EBOV stocks was extracted and the number of EBOV genomes calculated using Avogadro's number and the molecular weight of the EBOV genome. The limit of detection as judged by genomic standard is $3 \log (10) / \mathrm{mL}$. Virus titration was performed by plaque assay with Vero E6 cells from all serum samples as previously described (Moe et al., 1981). Briefly, increasing 10-fold dilutions of the samples were adsorbed to Vero E6 monolayers in duplicate wells $(200 \mu \mathrm{L})$; the limit of detection was $5 \mathrm{pfu} / \mathrm{mL}$. 
Total WBC, white blood cell differentials (monocytes, granulocytes, lymphocytes), RBC, PLT, HCT, HgB, MCV, $\mathrm{MCH}$, and $\mathrm{MCHC}$ were analyzed from blood collected in tubes containing EDTA using a laser based hematologic analyzer (Beckman Coulter). Serum samples were tested for concentrations of ALB, amylase (AMY), ALT, AST, ALP, GGT, GLU, cholesterol, TP, TBIL, BUN, CRE, and C-reactive protein (CRP) by using a Piccolo point-of-care analyzer and Biochemistry Panel Plus analyzer discs (Abaxis). 


\subsection{RESULTS}

In vitro antiviral activity of iminosugars against filoviruses. The antiviral activity of iminosugars UV-1, $-2,-3,-4$ and -5 in vitro against EBOV and MARV was assessed using a yield-plaque assay format and the $\mathrm{IC}_{50}$ of each compound was determined. Antiviral activity for all compounds was observed (Figure 1A-C) with UV-5 having the most antiviral activity ( $\mathrm{IC}_{50}$ of 7.859 and $6.359 \mu \mathrm{M}$ for EBOV and MARV, respectively) and UV-1 having the least $\left(\mathrm{IC}_{50}\right.$ of 32.95 and $47.74 \mu \mathrm{M}$ for EBOV and MARV, respectively). These values are substantially lower than the $50 \%$ cytotoxicity concentration $\left(\mathrm{CC}_{50}\right)$ for these molecules in Vero cells [Figure 1C and (Perry et al., 2013)], and provide a selectivity index (ratio of CC50 / EC50) of 4 to $>55$.

Efficacy testing of UV-4 and UV-5 in a mouse model of EBOV infection. The efficacy of UV-4, the active free base component of UV-4B, and UV-5, the most potent iminosugar tested in vitro, was first assessed using a mouse model of EBOV infection (Bray et al., 1998). In this study, C57BI/6 mice were administered 10 or $100 \mathrm{mg} / \mathrm{kg}$ of UV-4 or UV-5 via oral gavage or IP injection. Dosing started $\sim 1 \mathrm{~h}$ before infection with $\sim 1000$ pfu of mouse-adapted EBOV and was repeated BID for 10 days at approximately 12 hour intervals for UV-5 or TID at approximately 8 hour intervals for UV-4. The selected doses and schedule were based on tolerability studies in naïve mice. No efficacy was observed in the iminosugar treated mice as compared to the vehicle control (Figure 2AD).

EBOV guinea pig efficacy study with UV-4B. An efficacy study was conducted with UV$4 \mathrm{~B}$, the hydrochloride salt form of UV-4, using guinea pigs. The guinea pigs were 
treated TID for up to 10 days with UV-4B at doses equivalent to 6,12 or $24 \mathrm{mg} / \mathrm{kg} / \mathrm{dose}$ of UV-4 starting one day before infection. No survival benefit was observed at any dose level tested (Figure 3A). Early deaths were observed (Days 2-5) in all groups and were likely attributed to trauma during dosing, as these doses of UV-4 were previously shown to be well tolerated in uninfected animals (data not shown) and were observed in both UV-4 treated and vehicle control animals. Consistent with the survival results, the average weight losses of guinea pigs were not different in any of the groups (Figure 3B).

Tolerability and pharmacokinetic (PK) profile of UV-4B in macaques. A study was conducted to determine the tolerability and PK profile of UV-4B when administered TID every $8 \pm 0.5$ hours for five to ten consecutive days at escalating doses to female cynomolgus monkeys. All animals survived to the completion of dosing. During dose Cycles 1 to 3 , treatment with UV-4B (at doses equivalent to 20,60 , or $180 \mathrm{mg} / \mathrm{kg} / \mathrm{dose}$ of UV-4 TID for 5, 5, and 10 days, respectively) had no effect on physical examinations, post-dose, or cage-side observations other than one monkey that exhibited a rough hair-coat for three days during dose Cycle 3 (180 mg/kg/dose).

Treatment with UV-4B had no effect on body weights or body weight changes; all animals maintained a constant weight, or lost only a slight amount $(\leq 0.2 \mathrm{~kg})$ over the course of study (Figure 4A). Treatment with UV-4B at $180 \mathrm{mg} / \mathrm{kg} / \mathrm{dose}(540 \mathrm{mg} / \mathrm{kg} /$ day $)$ affected food consumption with more days described as 'fair' or 'poor' food consumption compared to non-treatment days or those during the 20 and $60 \mathrm{mg} / \mathrm{kg} / \mathrm{dose}$ treatment days. No treatment-related changes were noted in clinical chemistry (Supplementary 
Information, Table 1) or hematology (Supplementary Information, Table 2) at any dose level.

Assessment of the tolerability profile of UV-4B revealed differences in rodents and nonhuman primates, where significantly higher dose levels are tolerated by macaques dosed repeatedly with UV-4B. In the above described mouse and guinea pig studies, the highest dose levels tested (mouse and guinea pig doses of $100 \mathrm{mg} / \mathrm{kg}$ and $24 \mathrm{mg} / \mathrm{kg}$ of UV-4) are equivalent to $8.3 \mathrm{mg} / \mathrm{kg}$ and $5.2 \mathrm{mg} / \mathrm{kg}$, respectively, in humans based on body surface area calculations (FDA, 2005). In macaques dosed TID for 5-10 days with UV-4B, the maximum tolerated dose was determined to be $180 \mathrm{mg} / \mathrm{kg} / \mathrm{dose}$, which is equivalent to a human dose of $58 \mathrm{mg} / \mathrm{kg}, 7 \mathrm{X}-11 \mathrm{X}$ higher than doses tolerated in rodents. PK data from humans dosed with UV-4B during our Phase 1 clinical trial (unpublished) demonstrate a longer half-life than in rodents (Perry et al., 2013). Due to shorter half-life in mice the drug levels in plasma decline almost to zero three times a day before the next dose. The longer half-life observed in humans is mathematically predicted to result in increased trough level of drug, with drug accumulation after repeat oral dosing which is not seen in rodents. Due to limitations on volumes of blood which could be collected in the NHP tolerability study, complete PK data are not available. However, analysis of samples taken at $1 \mathrm{~h}$ after dosing (approximate $\mathrm{C}_{\max }$ ) demonstrate high levels of drug in plasma (Figure 4B), and samples taken at $8 \mathrm{~h}$ (immediately before the subsequent dose) confirm significant trough levels of drug (Figure 4B). These data indicated better efficacy profiles might be seen in primates (monkeys and humans) due to higher drug levels that could increase antiviral activity. 
Efficacy of UV-4B against EBOV in rhesus macaques. A small proof-of-concept study was designed to determine whether UV-4B could provide protection against lethal infection with an isolate of EBOV from the recent outbreak in West Africa (Makona strain) (Mire et al., 2015; Thi et al., 2015). A single control animal was shared with another study and was untreated but infected with the same virus challenge (target of $1000 \mathrm{pfu}$ ) at the same time as the UV-4B treated animals. The animals could only be treated once daily with UV-4B via naso-gastric tube, due to limitations on anesthesia and handling of the animals in the BSL-4 laboratory. The remaining two daily doses were attempted by spiking the test article into food or liquid (e.g., Pedialyte). Using this dosing regimen, three infected animals were treated for up to 10 days. All animals infected with the virus became clinically ill with symptoms consistent with EBOV infection. The development of symptoms was similar in all animals (Table 1). UV-4B treated animal 1204218 met euthanasia criteria on Day 7. UV-4B treated animal 1207127 met euthanasia criteria on Day 8. UV-4B treated animal 1205199 and the untreated control KB78 did not recover from anesthesia on Day 9 and were both euthanized. Viremia, as measured by $\mathrm{q}-\mathrm{PCR}$ and standard plaque assay methodologies, were also not different between the treated macaques and the control animal (Table 2). UV-4B treatment was not sufficient to prevent alterations in clinical chemistry (Supplementary Information, Table 3) or hematology (Supplementary Information, Table 4) laboratory values caused by EBOV infection. Examples of alterations in laboratory values include decreases in albumin, total protein and platelets levels and increases in BUN, ALT, AST, ALP, GGT, and CRP. 
Antiviral activity of UV-4 and UV-5 against MARV in rodents: Studies with MARV were carried out in parallel to EBOV efficacy studies. Since UV-4 and UV-5 were efficacious in vitro against MARV, the antiviral activity of iminosugars UV-4 and UV-5 was assessed following administration via PO dosing or IP injection in a mouse model of MARV using BALB/c mice (Warfield et al., 2009). When BALB/c mice ( $n=10 /$ group) were administered 10 or $100 \mathrm{mg} / \mathrm{kg}$ of UV-4 (free base) TID via oral gavage or IP injection, little to no survival benefit was observed (Figure 5A-B). When UV-5 was administered BID at 10 or $100 \mathrm{mg} / \mathrm{kg}$ via oral gavage ( $n=10 /$ group), no survival benefit was observed and the group of mice treated with $100 \mathrm{mg} / \mathrm{kg}$ of UV-5 showed significant toxicity (Figure 6A). Similar toxicity was observed when UV-5 was administered IP with the same dose regimen ( $n=10 /$ group). While mice administered 5 or $20 \mathrm{mg} / \mathrm{kg} \mathrm{UV-5}$ ( $n=20 /$ group) via IP injection were not protected from lethal challenge with MARV, mice treated with $10 \mathrm{mg} / \mathrm{kg}$ UV-5 were repeatedly protected against lethal disease (Figure 6B). These results were repeatedly observed in three separate studies ( $n=10 /$ study having 8,9 and 3 survivors, respectively) and resulted in a significant survival benefit observed in the UV-5 treated mice via IP route when compared to the vehicle control group ( $66.7 \%$ versus $0 \%$, respectively; $\mathrm{p}<0.0001$ by Log-rank Mantel-Cox test). In a single study performed using subcutaneous administration of UV-5, four of 10 mice treated with $10 \mathrm{mg} / \mathrm{kg}$ of UV-5 were protected compared to only two of the vehicle control mice (Figure 5C); however, this result was not statistically significant. Mice infected with MARV and treated with 5 or $20 \mathrm{mg} / \mathrm{kg}$ of UV-5 had no survival benefit, demonstrating a narrow therapeutic window for this test article. 
A single guinea pig study was conducted to assess the efficacy of UV-5 against MARV. Groups of 5 guinea pigs were infected with 1000 PFU of Marburg (Angola strain) and treated with $40 \mathrm{mg} / \mathrm{kg}$ of UV-5 BID via IM or IP injection. All groups succumbed to infection by Day 8 , ultimately displaying $0 \%$ survival (Figure 7A). During the course of this study, individual weights were monitored daily for each group. Interestingly, the average weights of the guinea pigs receiving UV-5 via IM injection were maintained throughout the study, unlike the other groups (Figure 7B); however, this indication of potential clinical benefit did not align with effect on survival of the animals. 


\subsection{CONCLUSIONS}

During the 2014-2016 EBOV epidemic in West Africa, many potential therapeutics were assessed for activity against filoviruses. In some cases, potential therapeutics with only in vitro data or with minimal in vivo data were rapidly advanced to human studies in response to the humanitarian crisis. Therapeutics, such as UV-4B, that were clinical stage candidates were given extra attention in the hopes that survival benefit might be observed and could be quickly transitioned to use in the clinic for the benefit of afflicted individuals.

The antiviral effects of glucosidase inhibition is validated in a recent publication by Sadat et al. (2014, New England Journal of Medicine), which showed that human cells lacking functional $\alpha$-glucosidase I were resistant to infection by viruses from divergent families. Inhibition of ER a-glucosidase enzymes would result in glycoproteins with glycans maintained in the $\mathrm{Glc}_{1-3} \mathrm{Man}_{9} \mathrm{GlcNAc}_{2}$ form, which prevents association with the chaperone proteins calnexin and calreticulin (Hammond et al., 1994). Viral glycoproteins are proposed to be more sensitive than host proteins to inhibition of glycosylation pathways due to their reliance on time-sensitive protein folding required for oligomerization. Lack of interaction with calnexin and calreticulin results in misfolding of viral glycoproteins and production of higher proportions of non-infectious virions, as demonstrated for influenza HA (Daniels et al., 2003), HIV gp120 (Fischer et al., 1995; Fischer et al., 1996a; Fischer et al., 1996b), HCV E2 (Qu et al., 2011) and bovine viral diarrhea virus E1/E2 (Branza-Nichita et al., 2001b; Durantel et al., 2005). The antiviral effect of iminosugars including UV-4B and UV-5 is linked to ER $\alpha$ glucosidases I \& II (Rawlings et al., 2009; Warfield et al., 2016b). While dependence on 
calnexin and calreticulin for proper protein folding has not been specifically demonstrated for EBOV or MARV glycoproteins, based on the literature data for numerous other viruses, it seemed a likely target for interference in the filoviral life cycle (Chang et al., 2013b). For instance, filovirus glycoproteins are highly glycosylated with more than half their molecular weight being attributed to carbohydrates primarily within the GP1 glycan cap and mucin-like domain but also in the GP2 (Jeffers et al., 2002). Modification of the glycosylation sites within both GP1 and GP2 have been shown to play roles in GP expression, structure, receptor binding, cell entry and evasion of immune responses (Lennemann et al., 2014; Lennemann et al., 2015). These observations, together with previous data demonstrating activity of iminosugars against filoviruses (Chang et al., 2013b; Chang et al., 2013c), justified exploring the activity of our iminosugars against filovirus infections.

Initial in vitro data for the iminosugars suggested activity against both EBOV and MARV in similar concentration ranges that have been observed as efficacious for both dengue and influenza, for which organisms the in vitro data translated to activity in vivo (Perry et al., 2013; Plummer et al., 2015; Stavale et al., 2015; Warfield et al., 2016a; Warfield et al., 2016b). The in vitro data suggested activity with acceptable safety margins in cells that could provide a therapeutic index. Unfortunately, the in vitro data did not translate into in vivo efficacy in rodents or nonhuman primates despite testing of several alternatives for dose, route, and regimen for delivery.

Several observations supported examination of potential survival benefit in nonhuman primates exposed to lethal filovirus challenge. A primate tolerability study demonstrated ability to administer a dose of UV-4B that was $\sim 10 \mathrm{X}$ higher in nonhuman primates than 
mice, with potential accumulation of the drug due to different pharmacokinetic profiles that had been demonstrated in an on-going human clinical Phase 1 study (not shown). The cell line used for in vitro studies was of nonhuman primate origin. The mouse and guinea pig challenge strains for EBOV are species adapted by serial passage and not 'wild-type virus' isolated directly from humans, unlike the nonhuman primate challenge viruses, which could affect the outcome of rodent studies. In one case, the mouseadapted EBOV has a small number of amino acid differences in the sequence of the glycoprotein compared to wild-type EBOV. While none of those amino acids are predicted to be directly glycosylated, the changes lie close to sites of glycosylation in the wild-type virus. These changes in the sequence could affect the structure, receptor binding and resulting infectivity of the mouse-adapted EBOV as compared to wild-type EBOV were used in primate testing. Additionally, it is known that glycans produced in many animals can be capped with both N-glycolylneuraminic acid (Neu5Gc) and Nacetylneuraminic acid (Neu5Ac) and can differ from human glycans that only produce glycoproteins containing Neu5Ac due to a mutation that inactivates cytidine monophosphate-N-acetylneuraminic acid hydroxylase (Irie et al., 1998). Species differences in glycosylation could have resulted in differential antiviral activity of UV-4B in mice and nonhuman primates, especially due to the fact that the surface glycoprotein of EBOV is highly glycosylated ( $17 \mathrm{~N}$-linked glycosylation sites are predicted).

While moderate efficacy was demonstrated for several iminosugars in vitro against EBOV and MARV, studies in mice were inconclusive with varied routes and doses having disparate results. Testing in guinea pigs and nonhuman primates did not reveal any more promising results, although limitations on dosing of infected primates prevent 
confirmation of dosing at the target levels and frequency. Thankfully, during the course of the outbreak, a number of therapeutic candidates were successfully identified as potential interventions for patients in need of treatment [reviewed in (Mendoza et al., 2016; Wong and Kobinger, 2015)]. 


\section{Acknowledgements}

The authors would like to thank Xiaoguo Zhan of Integrated BioTherapeutics for excellent technical support in compound preparations; Viktoriya Borisevich and Daniel Deer of UTMB Galveston for assistance with nonhuman primate studies; Jonathan Worden for tabulation of data; Matthew Duchars, Douglas Golightly, Mansoora Khaliq, and Brenda Wolling for critical review of the manuscript and Christina Hedberg, Aruna Sampath, Gary Wolfe and Sina Bavari for helpful discussions.

The studies described here were performed using sponsored research funds from Emergent BioSolutions (formerly Unither Virology, LLC). National Institutes of Health grant number UC7AI094660 provided BSL-4 operations support of the Galveston National Laboratory and were partially supported by Public Health Agency of Canada.

Opinions, conclusions, interpretations, and recommendations are those of the authors and are not necessarily endorsed by the U.S. Army or the University of Texas Medical Branch at Galveston. The mention of trade names or commercial products does not constitute endorsement or recommendation for use by the Department of the Army or the Department of Defense. 


\section{References}

Alonzi, D.S., Neville, D.C., Lachmann, R.H., Dwek, R.A., Butters, T.D., 2008. Glucosylated free oligosaccharides are biomarkers of endoplasmic- reticulum alphaglucosidase inhibition. The Biochemical journal 409, 571-580.

Branza-Nichita, N., Durantel, D., Carrouee-Durantel, S., Dwek, R.A., Zitzmann, N., 2001a. Antiviral effect of $\mathrm{N}$-butyldeoxynojirimycin against bovine viral diarrhea virus correlates with misfolding of E2 envelope proteins and impairment of their association into E1-E2 heterodimers. J Virol 75, 3527-3536.

Branza-Nichita, N., Durantel, D., Carrouée-Durantel, S., Dwek, R.A., Zitzmann, N., 2001b. Antiviral Effect ofN-Butyldeoxynojirimycin against Bovine Viral Diarrhea Virus Correlates with Misfolding of E2 Envelope Proteins and Impairment of Their Association into E1-E2 Heterodimers. Journal of Virology 75, 3527-3536.

Bray, M., Davis, K., Geisbert, T., Schmaljohn, C., Huggins, J., 1998. A mouse model for evaluation of prophylaxis and therapy of Ebola hemorrhagic fever. J Infect Dis 178, 651661.

Chang, J., Block, T.M., Guo, J.T., 2013a. Antiviral therapies targeting host ER alphaglucosidases: current status and future directions. Antiviral Res 99, 251-260.

Chang, J., Guo, J.T., Du, Y., Block, T., 2013b. Imino sugar glucosidase inhibitors as broadly active anti-filovirus agents. Emerg Microbes Infect 2, e77.

Chang, J., Warren, T.K., Zhao, X., Gill, T., Guo, F., Wang, L., Comunale, M.A., Du, Y., Alonzi, D.S., Yu, W., Ye, H., Liu, F., Guo, J.T., Mehta, A., Cuconati, A., Butters, T.D., Bavari, S., Xu, X., Block, T.M., 2013c. Small molecule inhibitors of ER alpha- 
glucosidases are active against multiple hemorrhagic fever viruses. Antiviral Res 98, $432-440$.

Dalziel, M., Crispin, M., Scanlan, C.N., Zitzmann, N., Dwek, R.A., 2014. Emerging principles for the therapeutic exploitation of glycosylation. Science 343, 1235681.

Daniels, R., Kurowski, B., Johnson, A.E., Hebert, D.N., 2003. N-linked glycans direct the cotranslational folding pathway of influenza hemagglutinin. Mol Cell 11, 79-90.

Durantel, D., Branza-Nichita, N., Durantel, S., Dweek, R.A., Zitzmann, N., 2005. The bovine viral diarrhoea virus: a model for the study of antiviral molecules interfering with $\mathrm{N}$-glycosylation and folding of envelope glycoprotein. Advances in experimental medicine and biology 564, 5-6.

Dwek, R.A., Butters, T.D., Platt, F.M., Zitzmann, N., 2002. Targeting glycosylation as a therapeutic approach. Nature reviews. Drug discovery 1, 65-75.

FDA, 2005. Guidance for Industry: Estimating the Maximum Safe Starting Dose in Initial Clinical Trials for Therapeutics in Adult Healthy Volunteers.

Fischer, P.B., Collin, M., Karlsson, G.B., James, W., Butters, T.D., Davis, S.J., Gordon, S., Dwek, R.A., Platt, F.M., 1995. The a-glucosidase inhibitor N-butyldeoxynojirimycin inhibits human immunodeficiency virus entry at the level of post-CD4 binding. Journal of Virology 69, 5791-5797.

Fischer, P.B., Karlsson, G.B., Butters, T.D., Dwek, R.A., Platt, F.M., 1996a. Nbutyldeoxynojirimycin-mediated inhibition of human immunodeficiency virus entry correlates with changes in antibody recognition of the V1/V2 region of gp120. Journal of Virology 70, 7143-7152. 
Fischer, P.B., Karlsson, G.B., Dwek, R.A., Platt, F.M., 1996b. N-butyldeoxynojirimycinmediated inhibition of human immunodeficiency virus entry correlates with impaired gp120 shedding and gp41 exposure. Journal of Virology 70, 7153-7160.

Hammond, C., Braakman, I., Helenius, A., 1994. Role of N-linked oligosaccharide recognition, glucose trimming, and calnexin in glycoprotein folding and quality control. Proceedings of the National Academy of Sciences of the United States of America 91, 913-917.

Hartman, A.L., Towner, J.S., Nichol, S.T., 2010. Ebola and marburg hemorrhagic fever. Clin Lab Med 30, 161-177.

https://clinicaltrials.gov/ct2/show/NCT02061358, NCT02061358: Randomized, DoubleBlind, Placebo-Controlled, Parallel Group, Single-Ascending Dose Study to Determine the Safety, Tolerability and Pharmacokinetics of UV-4B Solution Administered Orally in Healthy Subjects. U.S. National Institutes of Health.

Irie, A., Koyama, S., Kozutsumi, Y., Kawasaki, T., Suzuki, A., 1998. The molecular basis for the absence of N-glycolylneuraminic acid in humans. The Journal of biological chemistry $273,15866-15871$.

Jeffers, S.A., Sanders, D.A., Sanchez, A., 2002. Covalent modifications of the ebola virus glycoprotein. J Virol 76, 12463-12472.

Karlsson, G.B., Butters, T.D., Dwek, R.A., Platt, F.M., 1993. Effects of the imino sugar $\mathrm{N}$-butyldeoxynojirimycin on the $\mathrm{N}$-glycosylation of recombinant gp120. The Journal of biological chemistry $268,570-576$.

Lachmann, R.H., 2003. Miglustat. Oxford GlycoSciences/Actelion. Curr Opin Investig Drugs 4, 472-479. 
Lazar, C., Durantel, D., Macovei, A., Zitzmann, N., Zoulim, F., Dwek, R.A., BranzaNichita, N., 2007. Treatment of hepatitis B virus-infected cells with alpha-glucosidase inhibitors results in production of virions with altered molecular composition and infectivity. Antiviral Res 76, 30-37.

Leligdowicz, A., Fischer, W.A., 2nd, Uyeki, T.M., Fletcher, T.E., Adhikari, N.K., Portella, G., Lamontagne, F., Clement, C., Jacob, S.T., Rubinson, L., Vanderschuren, A., Hajek, J., Murthy, S., Ferri, M., Crozier, I., Ibrahima, E., Lamah, M.C., Schieffelin, J.S., BrettMajor, D., Bausch, D.G., Shindo, N., Chan, A.K., O'Dempsey, T., Mishra, S., Jacobs, M., Dickson, S., Lyon, G.M., 3rd, Fowler, R.A., 2016. Ebola virus disease and critical illness. Critical care 20, 217.

Lennemann, N.J., Rhein, B.A., Ndungo, E., Chandran, K., Qiu, X., Maury, W., 2014. Comprehensive functional analysis of N-linked glycans on Ebola virus GP1. MBio 5, e00862-00813.

Lennemann, N.J., Walkner, M., Berkebile, A.R., Patel, N., Maury, W., 2015. The Role of Conserved N-Linked Glycans on Ebola Virus Glycoprotein 2. J Infect Dis 212 Suppl 2, S204-209.

Mendoza, E.J., Qiu, X., Kobinger, G.P., 2016. Progression of Ebola Therapeutics During the 2014-2015 Outbreak. Trends Mol Med 22, 164-173.

Mire, C.E., Matassov, D., Geisbert, J.B., Latham, T.E., Agans, K.N., Xu, R., Ota-Setlik, A., Egan, M.A., Fenton, K.A., Clarke, D.K., Eldridge, J.H., Geisbert, T.W., 2015. Singledose attenuated Vesiculovax vaccines protect primates against Ebola Makona virus. Nature 520, 688-691. 
Moe, J.B., Lambert, R.D., Lupton, H.W., 1981. Plaque assay for Ebola virus. J Clin Microbiol 13, 791-793.

Organization, W.H., Ebola data and statistics.

Perry, S.T., Buck, M.D., Plummer, E.M., Penmasta, R.A., Batra, H., Stavale, E.J., Warfield, K.L., Dwek, R.A., Butters, T.D., Alonzi, D.S., Lada, S.M., King, K., Klose, B., Ramstedt, U., Shresta, S., 2013. An iminosugar with potent inhibition of dengue virus infection in vivo. Antiviral Res 98, 35-43.

Plummer, E., Buck, M.D., Sanchez, M., Greenbaum, J.A., Turner, J., Grewal, R., Klose, B., Sampath, A., Warfield, K.L., Peters, B., Ramstedt, U., Shresta, S., 2015. Dengue Virus Evolution under a Host-Targeted Antiviral. J Virol 89, 5592-5601.

Pollock, S., Dwek, R.A., Burton, D.R., Zitzmann, N., 2008. N-Butyldeoxynojirimycin is a broadly effective anti-HIV therapy significantly enhanced by targeted liposome delivery. Aids 22, 1961-1969.

Qu, X., Pan, X., Weidner, J., Yu, W., Alonzi, D., Xu, X., Butters, T., Block, T., Guo, J.T., Chang, J., 2011. Inhibitors of endoplasmic reticulum alpha-glucosidases potently suppress hepatitis C virus virion assembly and release. Antimicrobial agents and chemotherapy 55, 1036-1044.

Rathore, A.P., Paradkar, P.N., Watanabe, S., Tan, K.H., Sung, C., Connolly, J.E., Low, J., Ooi, E.E., Vasudevan, S.G., 2011. Celgosivir treatment misfolds dengue virus NS1 protein, induces cellular pro-survival genes and protects against lethal challenge mouse model. Antiviral Res 92, 453-460.

Rawlings, A.J., Lomas, H., Pilling, A.W., Lee, M.J., Alonzi, D.S., Rountree, J.S., Jenkinson, S.F., Fleet, G.W., Dwek, R.A., Jones, J.H., Butters, T.D., 2009. Synthesis 
and biological characterisation of novel $\mathrm{N}$-alkyl-deoxynojirimycin alpha-glucosidase inhibitors. Chembiochem : a European journal of chemical biology 10, 1101-1105.

Sadat, M.A., Moir, S., Chun, T.W., Lusso, P., Kaplan, G., Wolfe, L., Memoli, M.J., He, M., Vega, H., Kim, L.J., Huang, Y., Hussein, N., Nievas, E., Mitchell, R., Garofalo, M., Louie, A., Ireland, D.C., Grunes, C., Cimbro, R., Patel, V., Holzapfel, G., Salahuddin, D., Bristol, T., Adams, D., Marciano, B.E., Hegde, M., Li, Y., Calvo, K.R., Stoddard, J., Justement, J.S., Jacques, J., Long Priel, D.A., Murray, D., Sun, P., Kuhns, D.B., Boerkoel, C.F., Chiorini, J.A., Di Pasquale, G., Verthelyi, D., Rosenzweig, S.D., 2014. Glycosylation, hypogammaglobulinemia, and resistance to viral infections. The New England journal of medicine 370, 1615-1625.

Saito, T., Yamaguchi, I., 2000. Effect of glycosylation and glucose trimming inhibitors on the influenza A virus glycoproteins. J Vet Med Sci 62, 575-581.

Slenczka, W.G., 1999. The Marburg virus outbreak of 1967 and subsequent episodes. Curr Top Microbiol Immunol 235, 49-75.

Stavale, E.J., Vu, H., Sampath, A., Ramstedt, U., Warfield, K.L., 2015. In vivo therapeutic protection against influenza $A(\mathrm{H} 1 \mathrm{~N} 1)$ oseltamivir-sensitive and resistant viruses by the iminosugar UV-4. PLoS One 10, e0121662.

Thi, E.P., Mire, C.E., Lee, A.C., Geisbert, J.B., Zhou, J.Z., Agans, K.N., Snead, N.M., Deer, D.J., Barnard, T.R., Fenton, K.A., MacLachlan, I., Geisbert, T.W., 2015. Lipid nanoparticle siRNA treatment of Ebola-virus-Makona-infected nonhuman primates. Nature 521, 362-365. 
Warfield, K.L., Barnard, D.L., Enterlein, S.G., Smee, D.F., Khaliq, M., Sampath, A., Callahan, M.V., Ramstedt, U., Day, C.W., 2016a. The Iminosugar UV-4 is a Broad Inhibitor of Influenza A and B Viruses ex Vivo and in Mice. Viruses 8.

Warfield, K.L., Bradfute, S.B., Wells, J., Lofts, L., Cooper, M.T., Alves, D.A., Reed, D.K., VanTongeren, S.A., Mech, C.A., Bavari, S., 2009. Development and characterization of a mouse model for Marburg hemorrhagic fever. J Virol 83, 6404-6415.

Warfield, K.L., Plummer, E.M., Sayce, A.C., Alonzi, D.S., Tang, W., Tyrrell, B.E., Hill, M.L., Caputo, A.T., Killingbeck, S.S., Beatty, P.R., Harris, E., Iwaki, R., Kinami, K., Ide, D., Kiappes, J.L., Kato, A., Buck, M.D., King, K., Eddy, W., Khaliq, M., Sampath, A., Treston, A.M., Dwek, R.A., Enterlein, S.G., Miller, J.L., Zitzmann, N., Ramstedt, U., Shresta, S., 2016b. Inhibition of endoplasmic reticulum glucosidases is required for in vitro and in vivo dengue antiviral activity by the iminosugar UV-4. Antiviral Res 129, 9398.

Wong, G., Kobinger, G.P., 2015. Backs against the wall: novel and existing strategies used during the 2014-2015 Ebola virus outbreak. Clin Microbiol Rev 28, 593-601. 
Table 1: Clinical scores of UV-4B treated or untreated rhesus macaques infected with EBOV. Animals were monitored at least daily and scored for disease progression with a filovirus scoring protocol approved by the UTMB Institutional Animal Care and Use Committee. The scoring system includes assessments for posture/activity level, attitude/behavior, food and water intake, weight, respiration, and disease manifestations such as visible rash, hemorrhage, ecchymosis, or flushed skin.

\begin{tabular}{|c|c|c|c|c|c|c|c|c|c|c|}
\hline \multirow{2}{*}{ Animal ID } & \multicolumn{10}{|c|}{ Day Post Challenge } \\
\cline { 2 - 11 } & $\mathbf{0}$ & $\mathbf{1}$ & $\mathbf{2}$ & $\mathbf{3}$ & $\mathbf{4}$ & $\mathbf{5}$ & $\mathbf{6}$ & $\mathbf{7}$ & $\mathbf{8}$ & $\mathbf{9}$ \\
\hline $\mathbf{1 2 0 4 2 1 8}$ & 0 & 0 & 0 & 0 & 0 & 0 & 3 & 11 & --- & -- \\
\hline $\mathbf{1 2 0 5 1 9 9}$ & 0 & 0 & 0 & 0 & 0 & 0 & 0 & 1 & 3 & $3 / 19^{*}$ \\
\hline $\mathbf{1 2 0 7 1 2 7}$ & 0 & 0 & 0 & 0 & 0 & 0 & 0 & 4 & $6 / 11^{\wedge}$ & -- \\
\hline $\begin{array}{l}\text { KB78 } \\
\text { (control) }\end{array}$ & 0 & 0 & 0 & 0 & 0 & 0 & 0 & 1 & 1 & $3 / 14^{*}$ \\
\hline \\
^ Scores were before and after anesthesia \\
A score of $\geq 9$ indicated that an animal met criteria for euthanasia
\end{tabular}


Table 2: Comparison of viremia of UV-4B treated or untreated rhesus macaques infected with EBOV.

\begin{tabular}{|c|c|c|c|c|c|c|c|c|c|c|c|c|}
\hline \multirow{2}{*}{$\begin{array}{c}\text { NHP } \\
\text { ID }\end{array}$} & $\begin{array}{c}\text { Day 0 } \\
\text { (Prechallenge) }\end{array}$ & \multicolumn{2}{|c|}{ Day 3 } & \multicolumn{2}{c|}{ Day 6 } & \multicolumn{2}{c|}{ Day 7 } & \multicolumn{2}{c|}{ Day 8 } & \multicolumn{2}{c|}{ Day 9 } \\
\cline { 2 - 13 } & GE/mL & pfu/mL & GE/mL & pfu/mL & GE/mL & pfu/mL & GE/mL & pfu/mL & GE/mL & pfu/mL & GE/mL & pfu/mL \\
\hline $\mathbf{1 2 0 4 2 1 9}$ & $<3$ & $<0.69$ & 7.15 & 4.19 & 10.32 & 7.49 & 10.25 & 7.53 & --- & -- & --- & -- \\
\hline $\mathbf{1 2 0 5 1 9 9}$ & $<3$ & $<0.69$ & 6.35 & 3.14 & 9.44 & 7.20 & ND & ND & ND & ND & 10.04 & 7.38 \\
\hline $\mathbf{1 2 0 7 1 2 7}$ & $<3$ & $<0.69$ & 6.46 & 3.57 & 10.12 & 7.18 & ND & ND & 10.21 & 7.13 & -- & -- \\
\hline $\begin{array}{c}\text { KB78 } \\
\text { (control) }\end{array}$ & $<3$ & $<0.69$ & 2.54 & 2.54 & 7.33 & 7.33 & ND & ND & ND & ND & 6.13 & 6.13 \\
\hline
\end{tabular}

${ }^{*} \log _{10}$ of EBOV Genome Equivalents/mL in blood by qRT-PCR; $\log _{10} 3$ (Genome Equivalents) is limit of detection as judged by genomic standard.

\#log10 of EBOV pfu/mL in blood by standard plaque assay; the limit of detection was $5 \mathrm{pfu} / \mathrm{mL}$

ND: not determined/ no sample for time point 
Figure 1. Antiviral activity of iminosugars on filoviruses in vitro. The antiviral activity of UV-1, UV-2, UV-3, UV-4 and UV-5 were assessed in Vero cells using a yieldplaque assay format against (A) EBOV and (B) MARV. $($ (C) The $50 \%$ inhibitory concentrations $\left(\mathrm{IC}_{50}\right)$ were calculated for each iminosugar against EBOV and MARV using GraphPad Prism based on \% inhibition at each concentration. Note: The DMSO concentration was toxic at highest compound concentrations (62.5 and $125 \mu \mathrm{M})$ based on CPE observations and virus titer results.
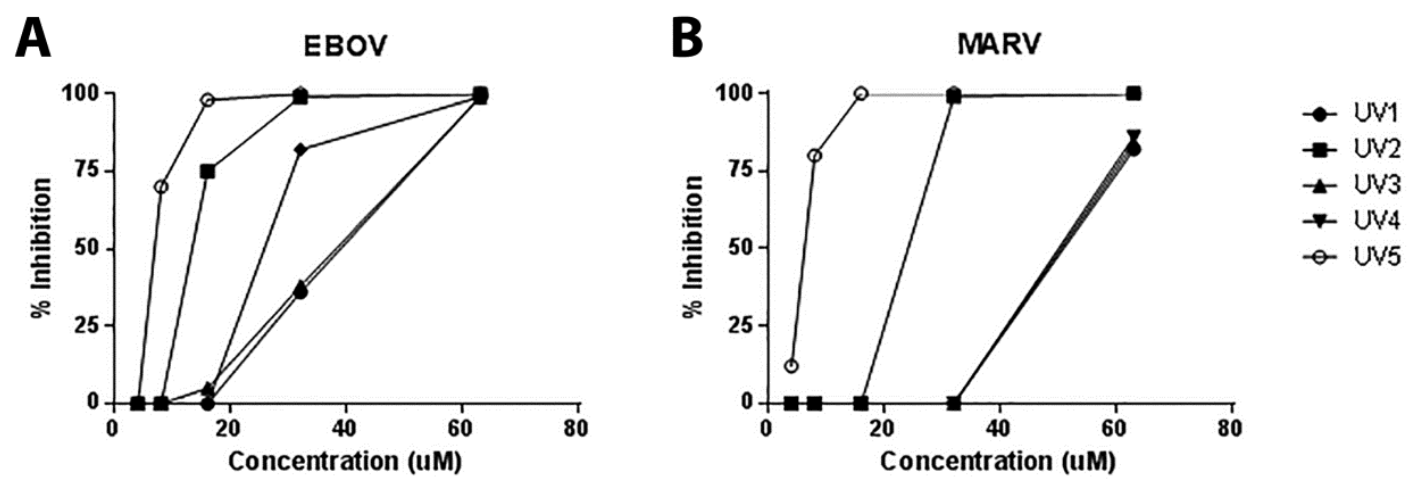

C
\begin{tabular}{|c|c|c|c|c|c|}
\hline & UV-1 & UV-2 & UV-3 & UV-4 & UV-5 \\
\hline EBOV IC $_{\mathbf{5 0}}(\mu \mathrm{M})$ & 32.95 & 15.22 & 34.98 & 29.97 & 7.859 \\
\hline MARV IC $_{\mathbf{5 0}}(\mu \mathrm{M})$ & 47.72 & 28.66 & 47.72 & 47.72 & 6.359 \\
\hline CC $_{\mathbf{5 0}}(\mu \mathrm{M})$ & $>500$ & 125 & $>500$ & $>500$ & 350 \\
\hline
\end{tabular}


Figure 2. Survival of UV-4B and UV-5 treated mice after infection with mouseadapted EBOV. C57BI/6 mice were administered (A, B) 10 or $100 \mathrm{mg} / \mathrm{kg}$ of UV-4 thrice daily (TID) or (C, D) UV-5 twice daily (BID) via oral gavage or IP injection starting at $\sim 1$ hour before infection for up to 10 days. All mice were challenged with $\sim 1000$ pfu of mouse-adapted EBOV and monitored for up to 14 days. Survival data is plotted as percent survival against days post infection. Graph shows survival of animals in each group.
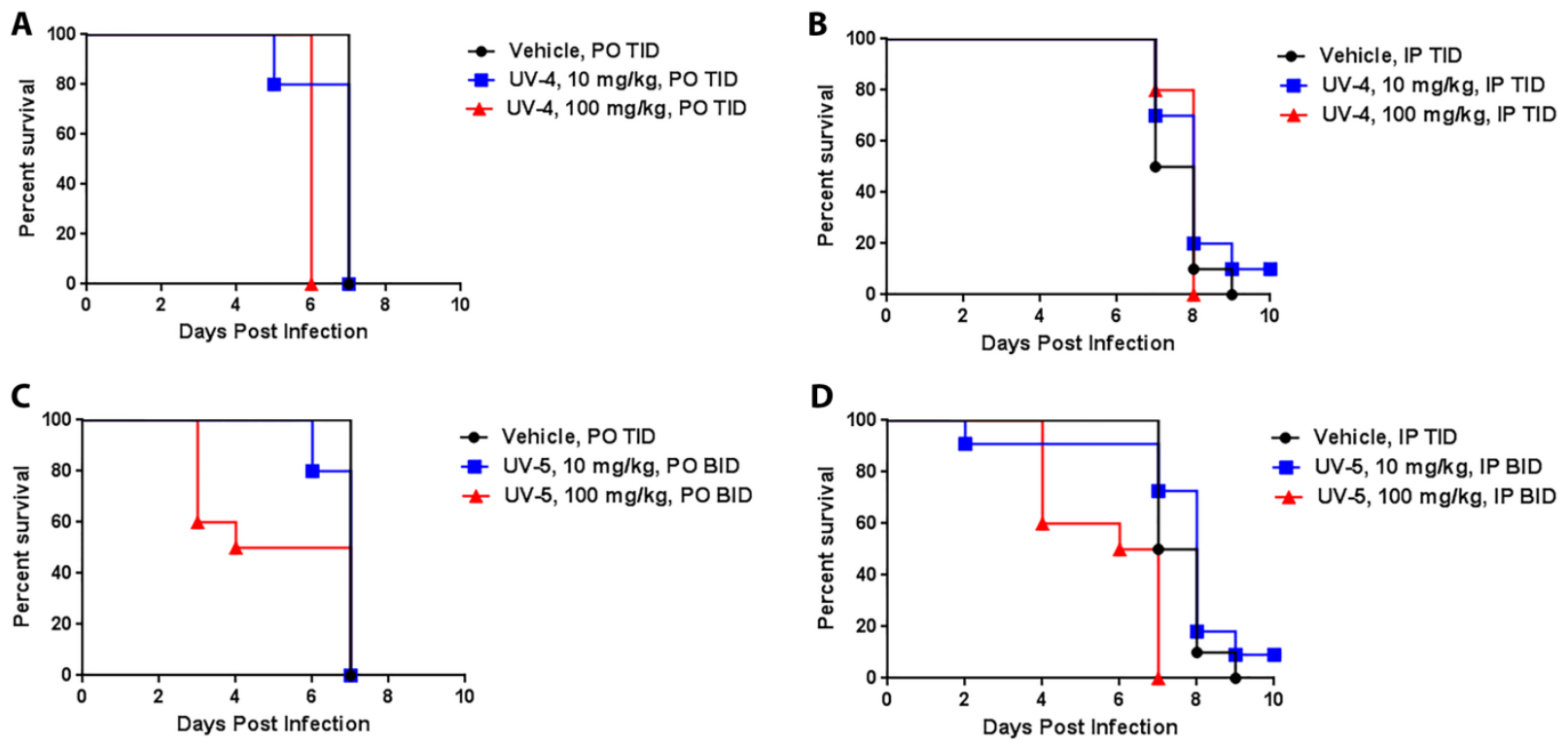
Figure 3. Treatment with UV-4 does not protect against lethal EBOV challenge in guinea pigs. Guinea pigs $(n=4)$ were treated orally with vehicle, 6,12 or $24 \mathrm{mg} / \mathrm{kg}$ of UV-4B thrice daily via oral gavage starting 1 day before infection. Guinea pigs were infected IP with guinea pig-adapted EBOV at a dose of $1000 \times L_{50}$. (A) Survival of infected guinea pigs grouped by treatment. Survival data is plotted as percent survival against days post infection. Graph shows survival of animals in each group. (B) Weights of infected guinea pigs grouped by treatment. Weight data is plotted as percent original weight against days post infection. Error bars represent the standard deviation of the mean.

A

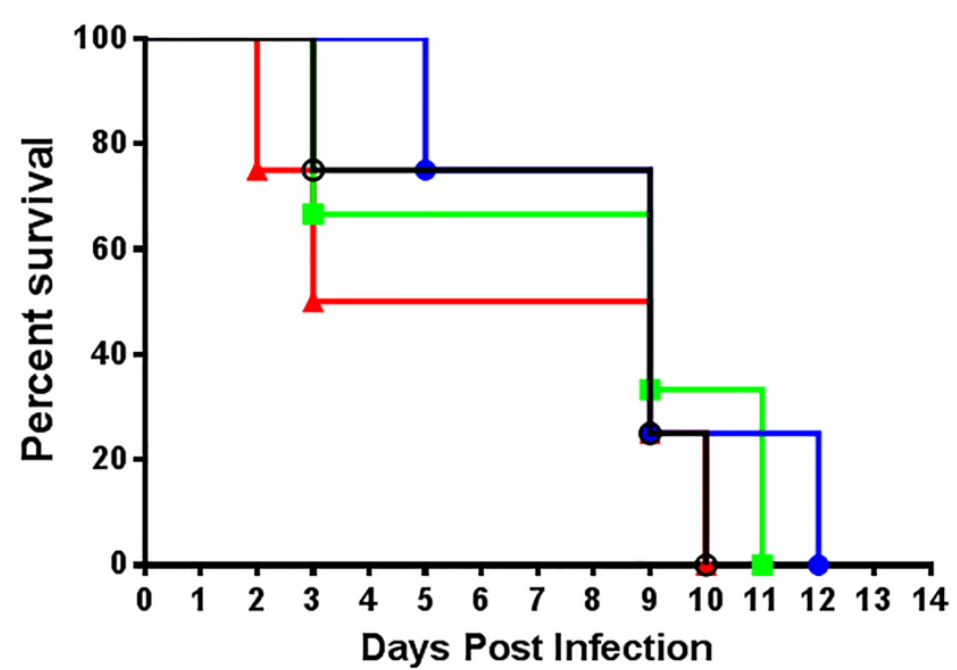

B

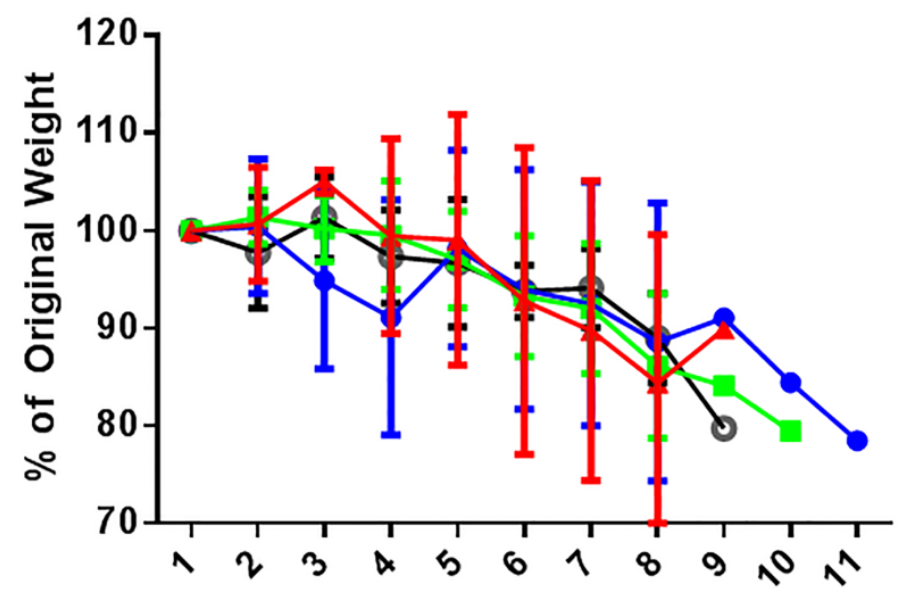

Days Post Infection $\vartheta$ Vehicle

- UV-4B, 6 mg/kg

- UV-4B, 12 mg.kg

$\pm U V-4 B, 24 \mathrm{mg} / \mathrm{kg}$ 
Figure 4. Tolerability and plasma exposure to increasing doses of UV-4B in macaques. Three female monkeys were dosed with UV-4 via nasogastric intubation TID for five days at dose levels of 20 and $60 \mathrm{mg} / \mathrm{kg}$ with a washout period of nine days in between dose levels. Following the second washout period, a third dose cycle was conducted at $180 \mathrm{mg} / \mathrm{kg}$ TID for ten days. Graphs (A) and (B) show data for each individual animal data plotted as different colors (NHP1, red; NHP2, blue; NHP3, black) for all data points recorded. (A) To demonstrate tolerability, weights of each animal were recorded daily through each dosing period. (B) To demonstrate exposure to the drug after oral dosing, plasma was collected from each animal immediately prior to dosing and at one hour and at eight hours after dosing for the third dose of UV-4 on the fifth day of each cycle. For the third dosing cycle $(180 \mathrm{mg} / \mathrm{kg}$ only) plasma was also collected immediately prior to dosing and at one hour and at eight hours after dosing for the third dose on the tenth day of that cycle. The level of UV-4 in the plasma of each sample was determined using a LCMSMS method. 

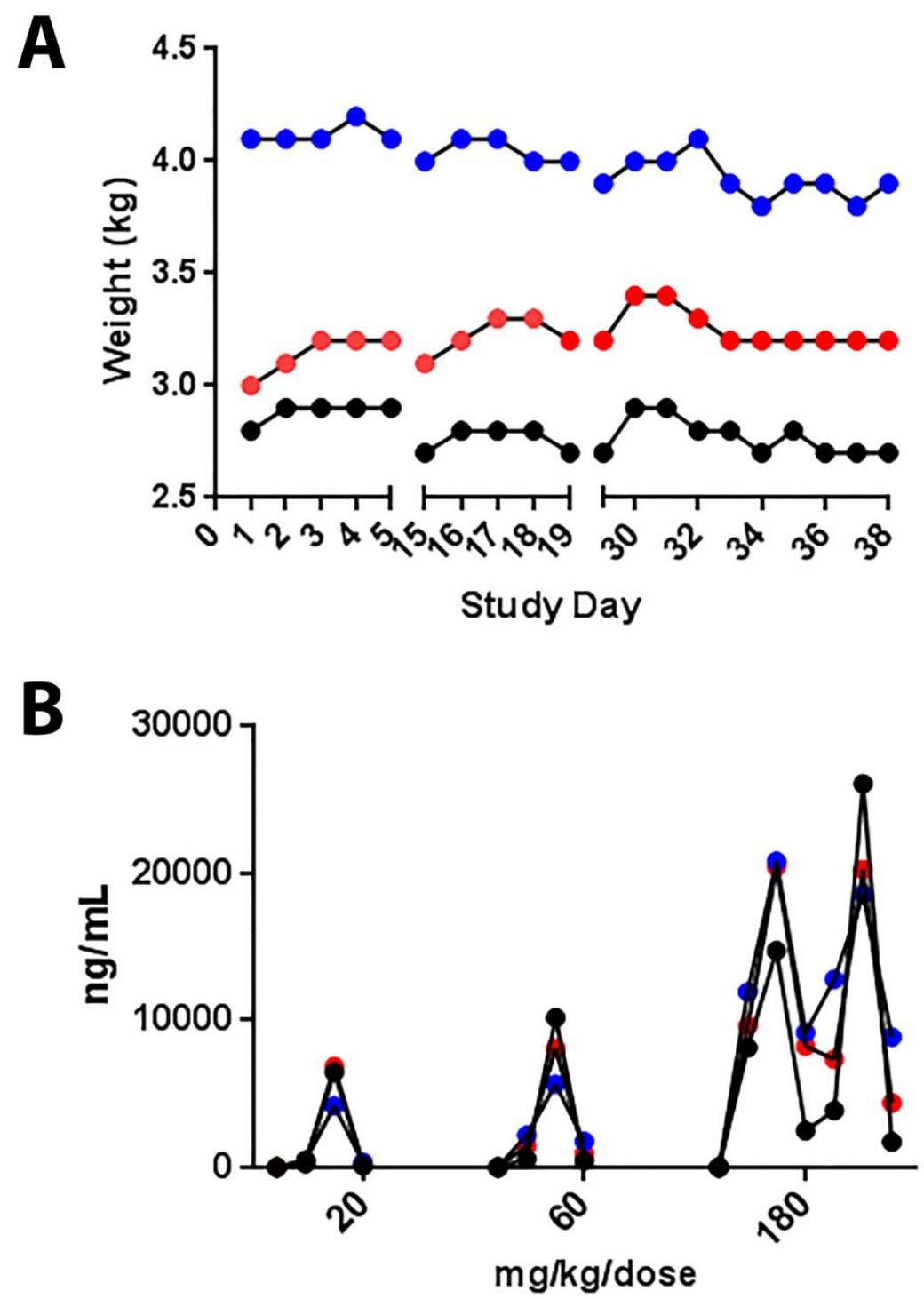
Figure 5. Survival of UV-4B treated mice after infection with mouse-adapted MARV-Ravn. BALB/c mice ( $\mathrm{n}=10 / \mathrm{group}$ ) were administered $(\mathbf{A}, \mathbf{B}) 10$ or $100 \mathrm{mg} / \mathrm{kg}$ of UV-4B thrice daily (TID) or vehicle only via oral gavage or IP injection starting at $\sim 1$ hour before infection for up to 10 days. All mice were challenged with $\sim 1000$ pfu of mouseadapted MARV-Ravn and monitored for up to 14 days. Survival data is plotted as percent survival against days post infection for each group.
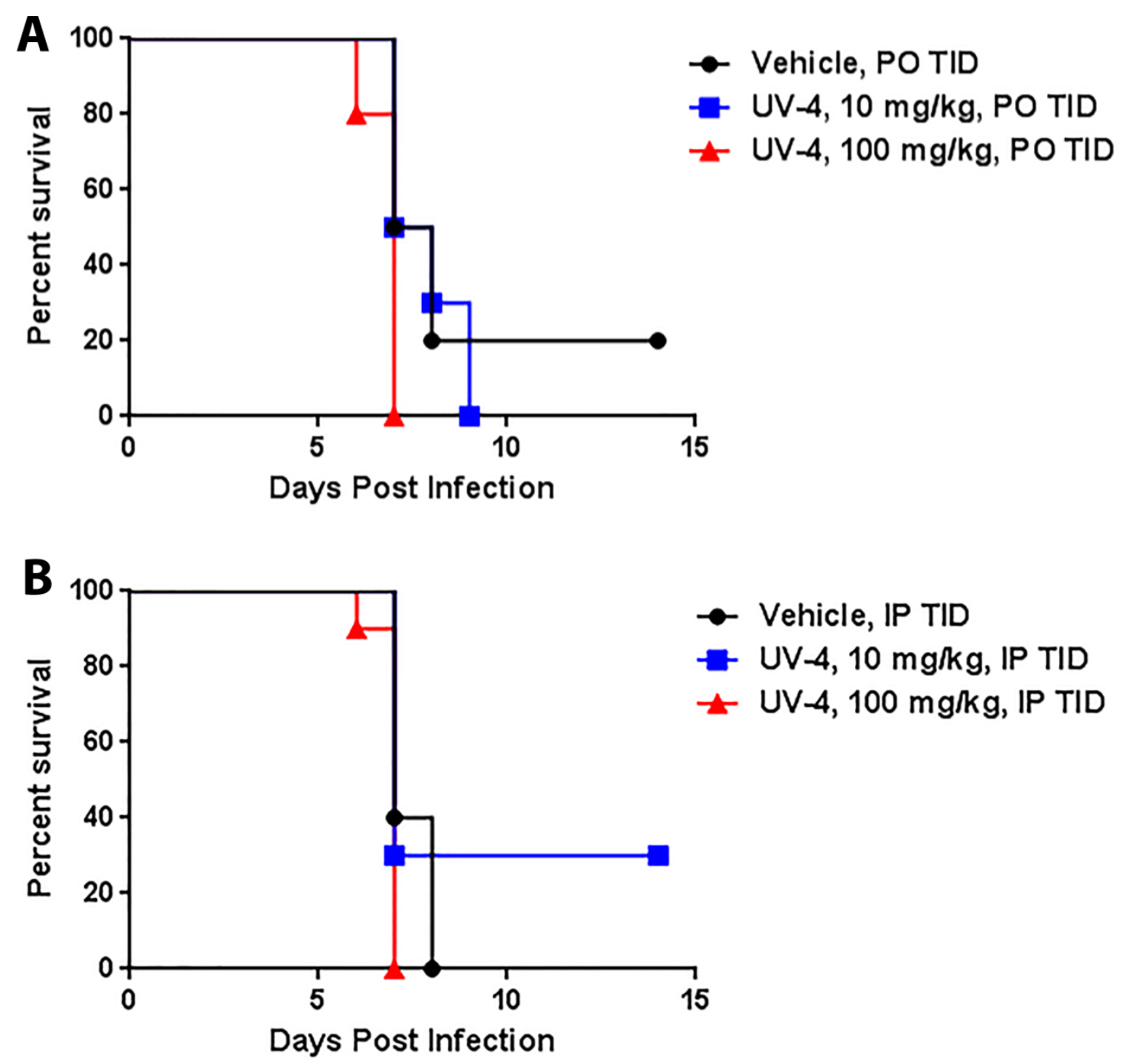
Figure 6. Survival of UV-5 treated mice after infection with mouse-adapted MARVRavn. BALB/c mice were administered (A) vehicle only, 10 or $100 \mathrm{mg} / \mathrm{kg}$ of UV-5 twice daily (BID) via oral gavage ( $\mathrm{n}=10 /$ group), (B) vehicle only, $5,10,20$ or $100 \mathrm{mg} / \mathrm{kg}$ of UV5 twice daily (BID) via intraperitoneal (IP) injection ( $n=10-20 / g r o u p)$, or (C) vehicle only, 5 , 10 , or $20 \mathrm{mg} / \mathrm{kg}$ of UV-5 twice daily (BID) via subcutaneous (SQ) injection ( $n=10 /$ group) starting at $\sim 1$ hour before infection for up to 10 days. All mice were challenged with $\sim 1000$ pfu of mouse-adapted MARV-Ravn and monitored for up to 14 days. Survival data is plotted as percent survival against days post infection. Graph shows survival of animals in each group.
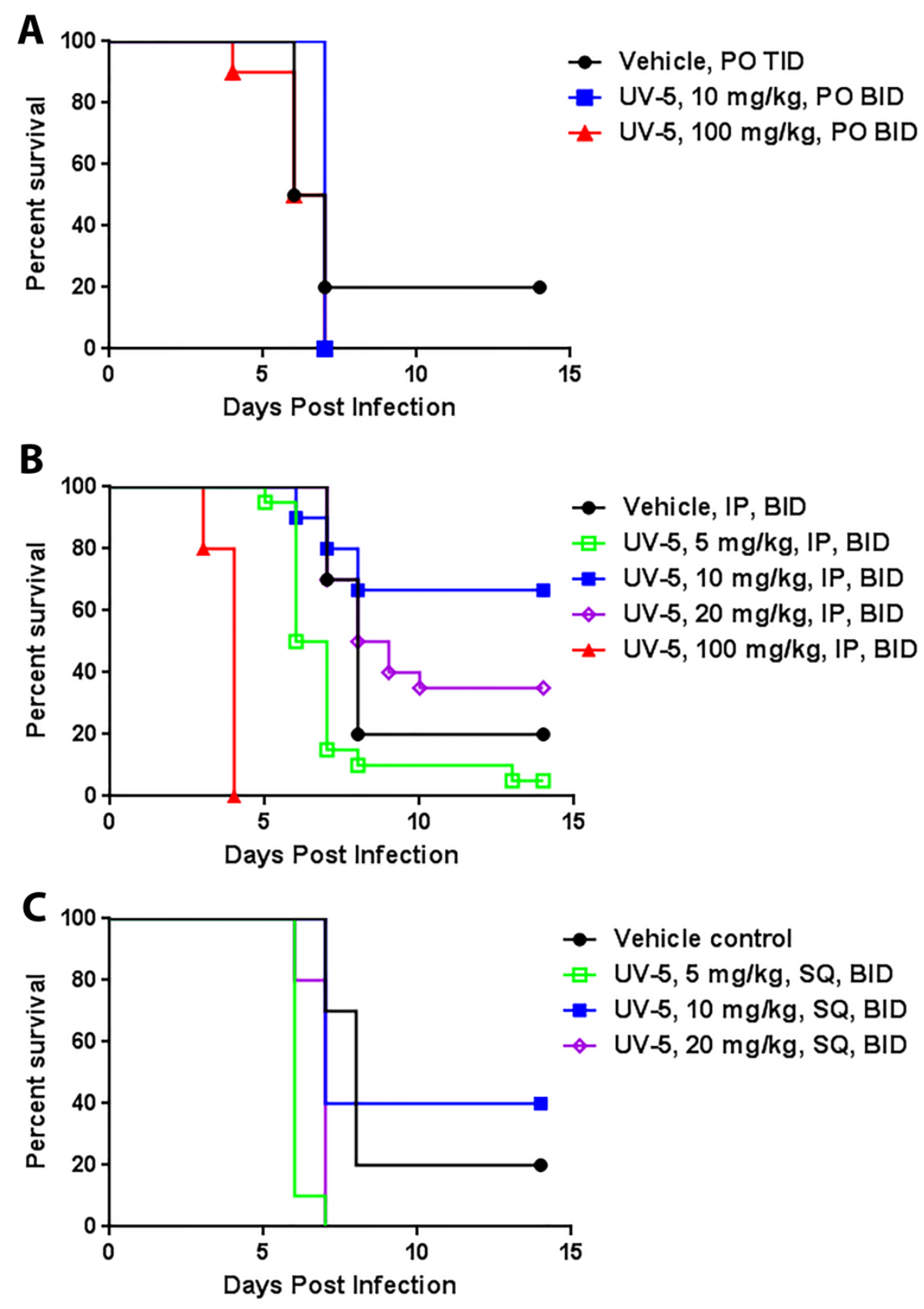
Figure 7. Treatment with UV-5 does not protect against lethal MARV (Angola strain) challenge in guinea pigs. Guinea pigs $(n=5)$ were treated with $40 \mathrm{mg} / \mathrm{kg}$ of UV-5 twice daily via IM or IP infection starting 1 hour prior to infection. Guinea pigs were infected IP with MARV at a dose of 1000 PFU. (A) Survival of infected guinea pigs grouped by treatment. Survival data is plotted as percent survival against days post infection. Graph shows survival of animals in each group. (B) Weights of infected guinea pigs grouped by treatment. Weight data is plotted as percent original weight against days post infection. Error bars represent the standard deviation of the mean.

A

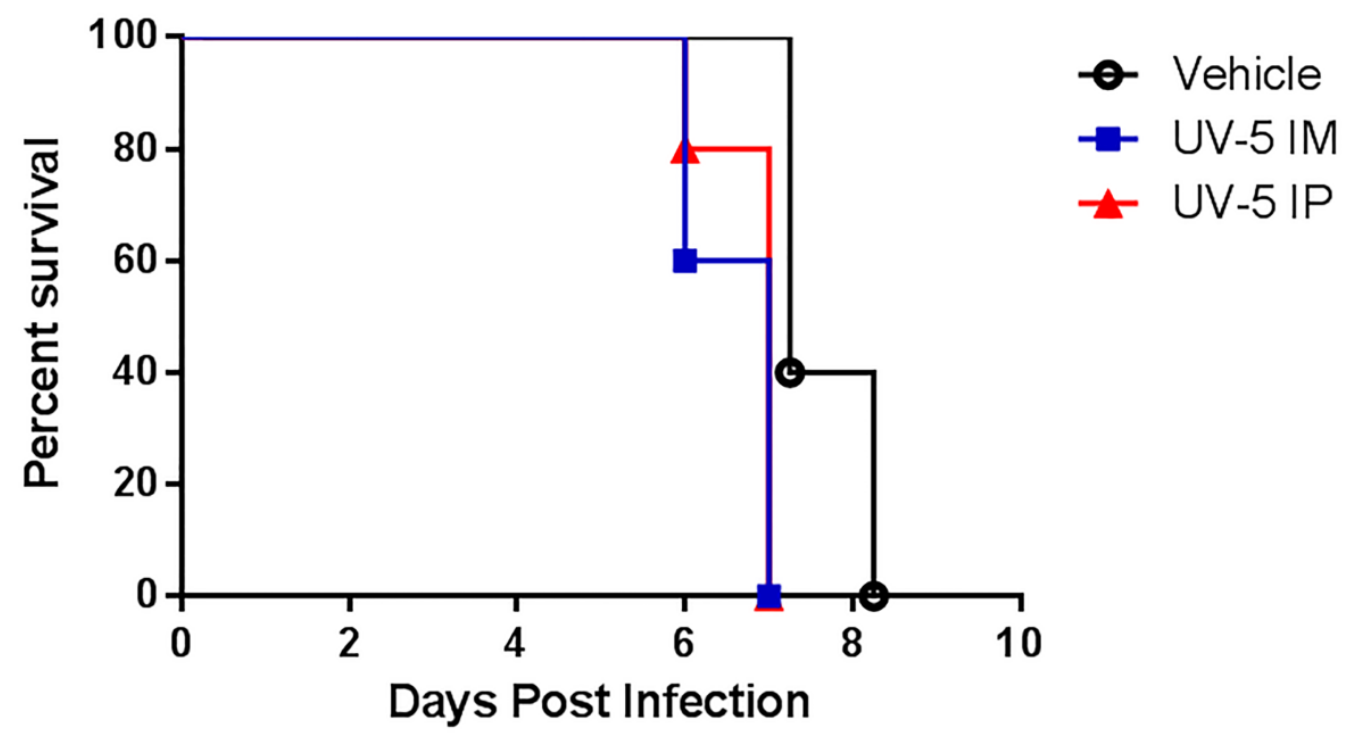

B

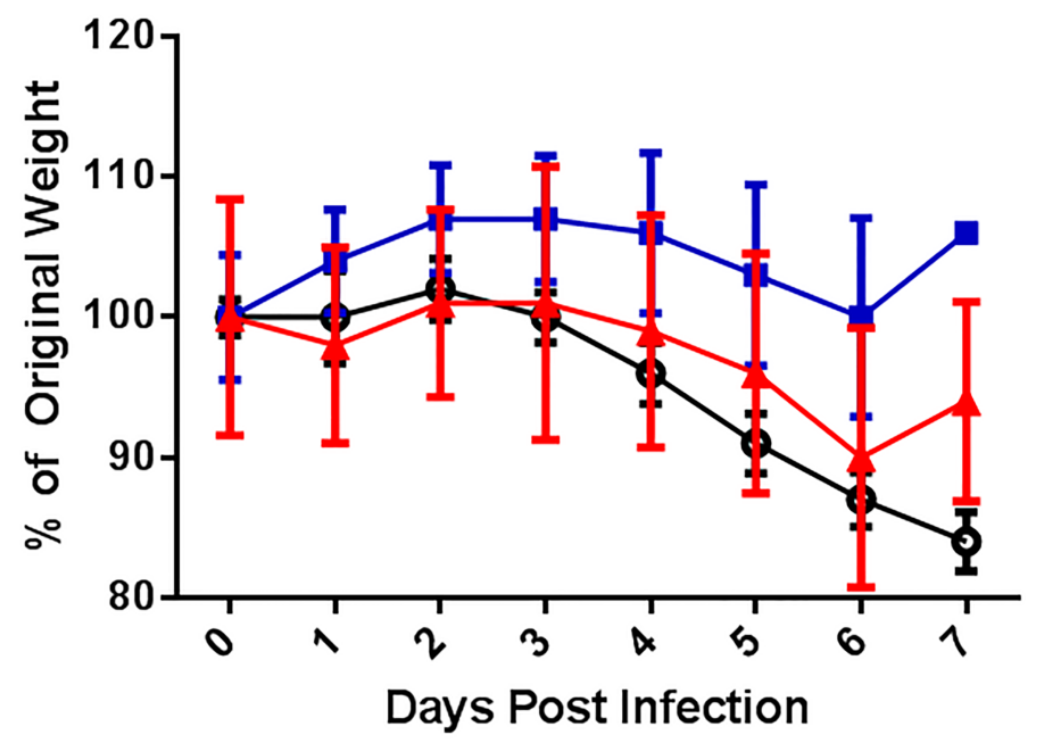

